\title{
Hacia una interpretación marxista de la historia puertorriqueña hoy: Manuel Maldonado Denis y el marxismo en Puerto Rico
}

Towards a Marxist interpretation of Puerto Rican history today: Manuel Maldonado and Marxism in Puerto Rico

\author{
Raúl Guadalupe de Jesús \\ Universidad de Puerto Rico en Bayamón - Centro de Estudios Avanzados de Puerto \\ Rico y el Caribe
}

\begin{abstract}
El libro de ensayos que presentamos hoy del intelectual puertorriqueño Manuel Maldonado Denis publicado por la editorial argentina Imago Mundi en la colección INDEAL, dirigida por el historiador Pablo Pozzi, vio la publicación por primera vez en el año de 1977 bajo el sello Editorial Antillana ubicada en Río Piedras. Previo a este texto, Maldonado había publicado varios estudios en los que se destaca Puerto Rico: una interpretación histórico-social publicada en 1969 por Siglo Veintiuno editores en la ciudad de México. Este último texto de nuestro autor recibió una reseña crítica por parte del historiador Gervasio García publicada en la revista La Escalera en 1970. Una crítica que Maldonado Denis luego acepta en el libro del que les voy a hablar hoy, Hacia una interpretación marxista de la historia de Puerto Rico y otros ensayos.
\end{abstract}

Cuarenta años después vuelve a publicarse este libro y uno se pregunta por la pertinencia. Si nos detenemos por un momento en el tiempo, diría contexto, en que se publicó por primera vez el libro de ensayos de Manuel Maldonado Denis el lector conocedor de la historia contemporánea nuestra se percatará que era sumamente pertinente la publicación y sus propuestas. Corrían los años de 1970 cuando en la coyuntura entre 1969 y 1976 la colonia industrial se encontraba asistiendo a un hervidero de luchas obreras, populares y políticas influenciadas por varios sectores de izquierda que se definían como marxistas, en sus distintas vertientes, entre ellas, el Partido Socialista Puertorriqueño.

A la par de todo este proceso de la historia material concreta en la academia puertorriqueña surgía una nueva escuela historiográfica influenciada de alguna manera por el marxismo occidental. Esta escuela es conocida como la Nueva historiografía puertorriqueña. Maldonado Denis en el ensayo central de su libro, con el que abre el mismo, apostó a que esta escuela vinculada a lo que se conoció como el Centro de Estudios de la Realidad Puertorriqueña iba a producir los estudios históricos necesarios que abrirían el camino hacia una interpretación marxista de la historia puertorriqueña. Los hechos nos han demostrado que la nueva historiografía devino en una tendencia historiográfica de un eclecticismo extremo en términos teóricos y metodológicos, y que se alejó de una interpretación materialista de la historia.

El autor de forma muy honesta nos dice que su ensayo no es una interpretación marxista sino un escrito que apunta hacia esa necesidad. Y expone que para dicha tarea el historiador que se la imponga se enfrentará “...con varios obstáculos importantes", el primero, es la ausencia de una tradición historiográfica marxista con un 
corpus investigativo sobre la realidad puertorriqueña, la segunda, la falta de una praxis histórica de larga duración guiada por los conceptos del materialismo histórico, la tercera, el dominio de las ideologías colonialistas burguesas en los campos de estudios científicos académicos, y por último, a la recepción tardía del marxismo en la historia de las ideas en la isla si lo comparamos con otras zonas geográficas de Latinoamérica y el Caribe.

Con una agudeza sofisticada el autor nos advierte la doble función del materialismo histórico, por un lado, la necesidad de la investigación concreta de la realidad histórico social que a su vez nos lleva a un tema muy sugerente sobre el papel del intelectual, y por otro lado, nos expone que la perspectiva materialista científica de la investigación en el marxismo está vinculada a producir un impacto transformador en la sociedad.

Otra perspectiva que hay que resaltar en la visión de Maldonado Denis es la que esboza en el siguiente planteamiento y cito: "En ningún momento pretendemos hacer de Marx un nuevo oráculo de Delfos, sino meramente explorar hasta dónde nos llevan sus teorías y su metodología" (Maldonado Denis, 2016:3).

Esa noción anti dogmática la podemos registrar en estos ensayos cuando por un lado reconoce que el colonialismo en Puerto Rico desde los tiempos de la colonia monárquica española hasta la colonia estadounidense de la primera mitad del siglo pasado y la colonia industrial de posguerra; se han adaptado al mercado capitalista mundial por medio del desarrollo desigual y combinado. La dinámica del desarrollo desigual y combinado ha impactado y moldeado a nuestras clases sociales, y ha impuesto en nuestra singular historia económica colonial unas mutaciones formales que no han desdibujado para nada los elementos del colonialismo clásico: el dominio político directo del territorio y el enclave de explotación económica. Muy sugerentemente nos dice que nuestro modelo colonial podríamos denominarlo como un "sistema de producción colonial" tomando el concepto del sociólogo brasileiro Florestan Fernandes (Maldonado Denis, 2016: 5).

Al definir la colonia de posguerra como una industrial no olvida su carácter de dependencia, la industrialización dependiente que impulso el imperialismo estadounidense entre 1940 y 1970 continúo con la destrucción de nuestra economía interna. Si en la primera mitad del siglo pasado el colonialismo de plantación azucarera destruyó la propiedad de manos puertorriqueñas, durante la segunda mitad, es decir en la posguerra, terminó de destruir la actividad agrícola del interior de la isla y aceleró la descomposición del campesinado puertorriqueño por medio de la emigración forzada. Los trabajos de Maldonado Denis, así como los de Luis Nieves Falcón, han sido la base para estudios recientes como el de John Stinson Fernández titulado, "Hacia una antropología de la emigración planificada: El negociado de empleo y Migración y el caso de Filadelfia" publicado en la RCS de la UPR en Río Piedras. Esto a manera de exponer la importancia que reviste no solo el ensayo de nuestro autor titulado "La ideología: emigración y neomaltusianismo" sino su libro Puerto Rico y Estados Unidos: emigración y colonialismo. Un análisis socio-histórico de la emigración puertorriqueña, (1976).

No obstante, y por tratarse de unos ensayos, que abren senderos de discusión de problemas más que el querer ofrecer argumentos definitivos, habría que mirar con suspicacia sus planteamientos sobre el papel histórico político del Partido Popular Democrático y el nacionalismo revolucionario anti-imperialista puertorriqueño. Un movimiento de masas no se constituye por triunfos electorales únicamente, si bien en sus inicios el PPD aportó a la articulación de una de las centrales obreras más importantes del país, la Confederación General de Trabajadores, esfuerzo que compartieron con los militantes del Partido Comunista, de orientación estalinista, y con los militantes del nacionalismo revolucionario, también el PPD se convirtió en la 
picota histórica para su desarticulación. Con relación al carácter del comunismo puertorriqueño de las décadas de 1930 y 1940 recién se comienza a realizar estudios historiográficos realizados por estudiantes graduados de historia. Lo mismo podríamos decir de los referentes políticos que nutrieron al nacionalismo revolucionario. En el Movimiento Libertador constituido por el Partido Nacionalista coexistían una pluralidad de perspectivas políticas que enriquecieron en algunos momentos los planteamientos anti imperialistas de dicho movimiento.

Si bien, Maldonado Denis apunta hacia la debilidad de la burguesía criolla de enfrentar la política demoledora del imperialismo estadounidense también nos alumbra sobre las razones concretas de esa imposibilidad. Esa clase social se convirtió en un agente mediador de la política imperial estadounidense, se convirtieron en los abogados financieros del saqueo de las propiedades puertorriqueñas por parte de las grandes centrales azucareras que tenían sus oficinas en la costa este de los Estados Unidos. Nombres como los de Luis Muñoz Rivera, José de Diego, Herminio Navarro y Eduardo Georgetti, entre otros, mantuvieron sus propiedades atadas al capital azucarero estadounidense como facilitadores de los procesos de expropiación de muchos propietarios puertorriqueños. Nuevas investigaciones en curso están arrojando luz al respecto y confirmando con evidencias lo que Maldonado Denis nos sugiere en sus ensayos.

La crítica del autor no se limita a la burguesía intermediaria local y a sus expresiones políticas sino que también se torna hacia el movimiento obrero y las expresiones políticas de esa clase. Aunque no se detiene en una crítica directa al sindicalismo de la American Federation of Labor (AFL), y a su sindicalismo empresarial y tradeunionista, sí perfila una crítica hacia la figura de Santiago Iglesias Pantín. Si bien ensayistas marxistas anteriores como Juan Antonio Corretjer y César Andreu Iglesias ya habían realizado un juicio crítico sobre Iglesias Pantin es Maldonado Denis uno de los que retoma la misma en la década de 1970 . Como en el terreno de las ideas hay una lucha social constante, como nos enseñará Mijail Bajtin, en el año de 1980 otro historiador puertorriqueño, Gonzalo F. Córdova, vuelve a reinstalar en el imaginario historiográfico nuestro el mito de Santiago Iglesias Pantín como creador del movimiento obrero puertorriqueño. Hoy sé de nuevos historiadores del obrerismo en la isla que con sus investigaciones han desmontado dicho mito.

El texto de Maldonado Denis todavía sigue siendo uno muy sugerente a los actuales debates historiográficos. Para muestra, además de mis argumentos anteriores, detengámonos en la crítica que nuestro autor expone en el ensayo "El imperialismo y la dependencia: el caso de Puerto Rico" al concepto de "imperialismo bobo" que desarrollara y difundiera el muñocismo, y que se reprodujera en el mundo de lo político en el Puerto Rico de la posguerra y que, además, adquiriera cierta resonancia en la academia. Nos dice Maldonado Denis: "La tesis del 'imperialismo bobo' es muy sencilla. Los Estados Unidos entraron en la guerra hispano estadounidense no por motivos expansionistas, sino porque súbitamente tuvieron que afrontar las responsabilidades de una potencia mundial" (Maldonado Denis, 2016: 26).

Nuestro autor partiendo de la propia historiografía estadounidense rebate dicha tesis. Historiadores como Walter La Feber, Warner van Alstyne y William Appleman Williams dan al traste con la tesis muñocistas recalcando que el carácter expansionista de los Estados Unidos fue uno planificado y conscientemente dirigido por su burguesía imperialista. Es importante este señalamiento porque durante las últimas décadas del siglo pasado y en las primeras del presente en nuestra historiografía se ha desarrollado una tendencia excepcionalista que vuelve a retomar la tesis del imperialismo bobo con otro lenguaje y otros matices. Incluso, esa tendencia también ha tenido ciertas resonancias en la literatura puertorriqueña. Estos ensayos de Manuel 
Maldonado Denis constituyen un excelente antídoto intelectual contra esa idea de la benevolencia imperial.

Manuel Maldonado Denis nos expuso la pertinencia de un análisis marxista de la realidad histórica para la década de 1970. Antes ya habían desfilado por los senderos de esta perspectiva autores como José Lanauze Rolón, José Enamorado Cuesta, Juan A. Corretjer, Juan Sáez Corales, César Andreu Iglesias, y los investigadores de la nueva historiografía, entre otros. Posterior a Maldonado Denis el análisis marxista se retoma en las investigaciones del colectivo el Taller de Formación Política, también en autores como Wilfredo Mattos Cintrón, Héctor Meléndez, Francisco Moscosso, entre otros. Si bien el materialismo histórico hoy ha sido marginado en términos generales de los estudios historiográficos y científicos sociales estoy convencido, como lo he dicho en otros escritos, de retomar los mismos desde una perspectiva abierta y científica.

Nuestro autor en estos ensayos nos ofrece algunos ejemplos de cómo trazar ese camino. Solo señalaré un ejemplo, en el primer ensayo con que abre el texto, Maldonado Denis nos expone la importancia de analizar la clase obrera industrial producto de Operación Manos a la Obra con el concepto desarrollado por Marx en El Capital de "superpoblación relativa" y sus tres categorías subyacentes: Flotante, Latente e Intermitente. Este llamado no lo hace con una intención de adopción a ciegas de esta categoría sino con el ejercicio teórico y metodológico de la adaptación a nuestra realidad, es de ahí que nos diga y cito que; "Marx nunca entendió su revolución teórica como un cuerpo de conocimiento capaz de trocarse en una teología escolástica" (Maldonado Denis, 2016: 22).

Es ahí en donde encuentro la fuerza argumentativa de estos ensayos. Los lectores de la obra de Manuel Maldonado Denis debemos dar gracias a los directivos de la editorial Imago Mundi y en especial a la colección INDEAL dirigida por nuestro colega continental Pablo Pozzi. 


\section{Bibliografía}

» Maldonado Denis, M. (2016). Hacia una interpretación marxista de la historia de Puerto Rico y otros ensayos. Buenos Aires: Imago Mundi. 
